\title{
Impact of Citizens' Economic Status on Policy Formulation and Implementation
}

\author{
Joash Ntenga Moitui \\ Thematic Centre for Governance and \\ Regional Integration, Cameroon
}

Citizenship can be defined as the judicial and political status given to individuals as equal members of a national community that both oblige them to undertake personal responsibilities and entitle them to individual rights. Social citizenship is ideally derived from this central definition; however, it extends to economic welfare as an added advantage of being a citizen of a country. The dynamic of public policy refers to the formulation of law and alignment of government funds towards social amenities that are beneficial to all citizens in a country. Public policy analysis relates to the determination of the most viable policy to adopt in a country in relation to the goals of its government with regard to public service (Dwyer, 2010). Public policy outlines nine main areas in the efficient running of society. The first is criminal justice, where policy is assocated with the punishment of crimes committed against other people or against the state (Dwyer, 2010). Culture and society also represent public policy with issues such as the arts and abortion. Budgets and taxes constitute economic policy. The others include education, health, government operations, environmental policy, social welfare and foreign affairs. Social citizenship plays a significant role in the formulation and implementation of these policies.

The function of the government is to secure conditions that allow individuals within its borders to secure their own livelihood through their own efforts. As such, it is the responsibility of the government to provide sufficient conditions for human development, financially, socially, emotionally and physically (Kolberg, 1992). All these elements relate to the presence of reliable education systems, adequate security, excellent and affordable health care, proper housing and most of all, an equitable chance of guaranteeing employment. These elements should be available to each and every citizen despite their age, race, social status, marital status and physical ability. The paper will constitute a research that will be undertaken to find 
out how social citizenship affects the formulation and implementation of public policy.

\section{Policy Formulation and the Contextualization of Thomas Humphrey Marshall Social Concept}

In the designing and implementation of policy, policymakers usually have some factors to consider. These factors include: the total population in the country, the constitution of the population in terms of race, age and physical ability, diversity of the society in terms of religion and culture among others. The general purpose of the paper will be to find out how these factors influence the making and execution of policy (Evers, 2013). For instance, public policy relating to the culture and society bracket includes sensitive issues such as abortion and gay rights. Depending on the nature of the community, policymakers will react accordingly. In conservative societies, for example, these two issues are banned as a matter of public policy.

Thomas Humphrey Marshall coined the term social citizenship. The main argument advanced by Marshall was related to the fact that the ideal experience for the citizenship was where the citizens would have a significant access to the civil rights, political rights, as well as the social rights in the given state where they lived or occupied. It must be noted that social citizenship to Marshall entails a whole range of rights, for instance, a modicum of security and economic welfare to the right of the citizens to be able to share fully in the social heritage of the country. T. H. Marshall also noted that the social citizenship entailed promotion of a civilized based on the standards that were prevailing in the society at the time. $\mathrm{T}$. H. Marshall in his essay, 'Citizenship and the Social Class,' noted that social citizenship denotes the social responsibilities that the states owe the citizens of the countries where they belong. Marshall pointed out to the fact that there was a great evolution of the rights of the people in England due to the fact that majority of the people had acquired the citizenship. There was an evolution from the $18^{\text {th }}$ century when the focus was on the civil rights to the $19^{\text {th }}$ century when the focus moved to the political rights then to the $20^{\text {th }}$ century when the focus advanced to the social rights of the citizens (Marshall, 2005). T. H. Marshall focused on three main factors that would aid in the enhancement of the $20^{\text {th }}$ century social rights evolution. Firstly, he focused on the fact that the development of the social rights of the citizens would be achieved through the granting of more rights to the citizens as well as the enlargement of the citizenship in the country. Secondly, T. H. Marshall focused on the need for the expansion of the area of common experience and common culture. The third point of view that was central to the achievement of social citizenship according to T. H. Marshall was the need to ensure that the income gap between the individuals in the society be lessened. It should be noted 
that the majority of the conceptions that were made by T. H. Marshall have played an instrumental role in ensuring that the policies of the different states of the world, for example, the United States (US) have adopted some of the social responsibilities that were conceived by T. H. Marshall. It must, however, be noted that majority of the social responsibilities of the states that were conceived by Marshall's idea of the social citizenship have led to some fiery debates primarily based on the effectiveness of some of such programs (Murray, 2007). The United States Social Security is one of such programs that were modeled around the T. H. Marshall's conceptions of social citizenship that has been faced with a number of criticisms.

Marshall's views on social citizenship significantly bordered on the social democracy as it had been noted that he was a practicing egalitarian liberal who believed in the fact that the PWWS that was enacted by the United Kingdom's Labour government was an example of democratic socialism due to the fact that it entailed a significant amount of state welfare (Dwyer, 2010). He developed significant attachments to the largely unconditional and universal welfare rights just as a majority of the social democrats in the UK and the US amongst other world's social democracies (Marshall, 2005). Secondly, Marshall's view was contrary with regards to the view of many of democratic socialist especially based on the fact that they saw class struggle as a factor that was imperative in the formation of the social citizenship in the countries. Marshall and the other supporters of the concept of the social citizenship, for instance Titmuss, were of the view that the British industrial capitalism evolutionary development was the hallmark of the emergence of the social rights practiced in the UK, rather than the class struggle as was suggested by the democratic socialists. Marshall also noted that there was a great level of optimism that was the greatest motivation that was driving the human nature. T. H. Marshall noted that rather than engage in class struggle, the citizens would mostly behave in a dignified and responsible manner while they are looking for the ways through which they could be able to enhance not only their lives but also the lives of the people who belong or live in their national community. Marshall went ahead to state that the individuals used the social right for the common interest of all the people rather than for their own narrow self-interests.

Later in the life of T. H. Marshall, he significantly moved away; somewhat from the values that he represented in his earlier life. Earlier, he was an ardent supporter of the social democracy, for instance, the focus on the fact that citizens should be able to have a number of rights such as; the universal welfare rights, social integration, the equality promotion as well as the freedom from any forms of deprivation including material deprivation. Later in the life of Marshall, he became restless and nervous about the relative ease with which the welfare benefits could 
be achieved by the different people as well as the effects that the self-interested citizenry were having on the rights (Marshall, 2005). Marshall noted that the abuse of the rights was very rife. The abuses that led to the concern by T. H. Marshall included the fraud by the business people and the claimants of the social welfare benefits as well as the frequent strikes in the public sector.

However, the social citizenship conception by T. H. Marshall has been criticized by a number of scholars and policy practitioners as being too ideal and that is can only be applied to the white able-bodied male and not all the citizens who are found in a country. The work of T. H. Marshall received a number of criticisms from both the feminists and the neo-liberals. The feminists mostly argued that the conditions that were prescribed by Marshall were only applicable for the working able-bodied - white men due to the fact that only the men enjoyed a massive level of ability to exercise their civil and political rights as well as the legal freedom that was of great importance to the central concept of the social citizenry as conceived in the work of Marshall (Murray, 2007). The feminists noted that Marshall failed to recognize that the women were second class citizens as they could not be able to have access to the factors that the white working male could be able to access. The feminists noted that Marshall made an enormous error by failing to acknowledge the racial and gender hierarchies that existed in not only Britain but also in the US and other countries of the world. T. H. Marshall later responded to the criticism by noting that citizenship in the different countries has in many cases functioned as an architect of the inequality in the society.

Secondly, the criticism from the neoliberals was mostly based on the fact that the social rights that were proposed by Marshall led to a significant amount of state control, while to them (the neoliberals), the foundation of a good society could only be built when the state significantly abstained from the economic protection of the society (Murray, 2007). To the neoliberals, the social responsibilities of the state in helping the poor to effectively utilize their political and social rights have created a significant level of passivity in the poor through the creation of a dependency culture in the society while not bringing any forms of improvement to the livelihood of the people.

There are a number of scholars who have considered the effects of the economic abilities of the citizens in influencing the formulation and the implementation of the public policy. Lipsmeyer (2011) noted that the economic climate that has an effect on the economic abilities of the citizens has a great influence on the formulation as well as the implementation of the public policy. Lipsmeyer noted that welfare policy in many countries of the world was greatly affected by the economic conditions. Lipsmeyer (2011) noted that a number of scholars, for instance, Hicks and Swank (2002), Blais, Blake and Dion (1993) and Allan and 
Scruggs (2004) have all noted that the economic ability of the different citizens usually have a great influence on the public policy formulation and the implementation (Lipsmeyer, 2011, p. 959). The economic abilities of the citizens influence the public policy in a positive manner, for instance, during periods of economic downturn, even the governments that are highly conservative and do not support the provision of assistance to the people who are unemployed usually engage in the development of policies that will ensure that the people are effectively buffered from the hardship that they may have bee faced with. Lipsmeyer (2011) further noted that the economic abilities of the citizens also have a significant level of influence on the public policy especially if the economic abilities of the citizenry are faced with great constraints. The governments will have a high level of freedom in making the public policy at the times when the country does not face any economic pressures. Analytical economic research has also indicated that the power of the government can also have a great influence on the public policy formulation and the implementation. The government power, in this case, refers to the ability of the government to pass the public policy legislations over the objections that are raised by the opposition (Lipsmeyer, 2011).

Schlesinger (2011) was also in agreement with the view that was raised by Lipsmeyer. He noted that economic abilities of the citizens had a great influence on the formulation and the implementation of the public policy. He gave the examples of the financial crises that have been faced in the US as having given rise to the pubic policy programs that were geared towards cushioning the Americans against the risks that they would have been faced within the country. In the UK, the economic deprivation of the British people, immediately, following the World War 1 led to the acceptance of the public policy health reforms. It has been noted by a number of scholars that the economic instability of the people lead to a situation where there is a popular support for the welfare state, and thus the public policy formulation and the implementation is a product of the economic abilities of the people. During the periods of the crisis, the economic abilities of the people are greatly reduced thus the majority of the public policies that gather greater levels of support amongst the general public in the different countries as those that support social welfare (Huber \& Stephens, 2001). It has been noted in research that when the economic abilities of the citizens are faced with great variety of risks, the support for the public policy formulation and implementation amongst the citizens will depend on the priorities that the citizens have. In the situations where the economic abilities of the citizens are reduced to the household level, there would be greater levels of attributions of causality and blame thus the public policy formulation and implementation may be murkier thus the process of the public policy making may be rendered less clear i.e. when the policy that is being implemented should be implemented at the collective or the individual level. 
Moreover, there have been some scholars that have noted that the economic abilities of citizens to influence the public policy have led to a situation where majority of the people have a greater ability to be able to influence the public policy as well as impose the ideas that the country may not have been involved in if the economic abilities of the citizens were higher. Whitaker etal (2012) noted that the public policy formulation and implementation are highly dependent on a number of factors such as the demands for different types of public policy that are specific, the economic abilities of the citizens as well as the intergovernmental pressures that are mostly associated with the federalism especially in the US.

\section{Economic Abilities of Citizens Influence the Formulation and Implementation of Public Policy}

The influence of the citizens' economic abilities in the formulation and implementation of public policy has been noted in a number of different countries in the world. The various examples with regards to how the economic abilities of the citizens in the different countries have had an influence in the public policy formulation and implementation will be considered. First, the economic difficulties that were faced by the people in Denmark due to the rise in the rates of the unemployment led to formulation and implementation of public policy that were geared towards the reduction in the dependency on the welfare (Huber \& Stephens, 2001). The public policies that were formulated and implemented in the country were geared towards the reduction of the rates of the unemployment in the country. I must be noted that the policies that were enacted by Denmark were geared towards the shielding of the lowly paid workers from the cuts that were being implemented by the government.

Seeleib-Kaiser (2001) noted that the public policy formulation in Germany, especially with regards to the welfare and the social citizenship, was based on heavy transfer but lean service. The economic ability of the people of Germany has had a great influence on the formulation as well as the implementation of the public policies especially those that are related to the social citizenship in the country. Due to the potential for the reduced economic abilities for the old, the public policy that was used in the country significantly raised the benefits that were received in the old-age insurance to a situation where they not only received higher old age benefits, but they were also indexed so that they could be bale to receive even higher benefits in the future. It must be noted that due to the reduced economic abilities of the old, the West Germany government made significant changes in the late 1950s that ensured that by the mid 70s, the old age benefits that were received by the people were enough to be able to allow for the people to rely effectively on the government support alone for their needs. 
It can further be noted that the economic abilities of the citizens play an important role in the formulation and the implementation of the public policy in a number of instances. It has been noted that in the liberal welfare states, the people who belong to the low-income group usually determine the public policies that are being implemented. Here, the people who have the low-income levels are the majority thus the public policies that are being formulated and implemented must be focused on the provision of the welfare benefits, for instance, universal transfers as well as the provision of social insurance to the citizens (Esping-Anderson, 1990). It is of great importance to note that a number of countries, for instance, Australia, Canada and the United States have made use of the model as without the subsidization of the social insurance as well as a host of other elements that are important to the vast majority of the people who are faced with the poverty, there will be a little support for the regime. The economic crisis that was a result of the collapse of the subprime mortgage lending market led to a situation where the economic capacity of a number of people was reduced. The effect was a reduction in the economic ability of the people thus they significantly supported the public policies that were associated with the improvement of the employment compensation as well as the increase in the healthcare and other social benefits.

In Sweden, low economic ability of the citizens due to effects of the rising levels of the unemployment in the country created to a situation where the public policy that was made supported the interests of the state rather than the earlier situation where there was a reduction in the levels of the competition that was offered to the different people who were found in the country. The new public policy that was enacted after the elections in 1982 led to a situation where there was an increase in the welfare spending. However, it can be noted that in some of the instances that were recorded in the country, the spending cuts were put on the welfare thus significantly reducing the capacity of the people who were in the lower and medium levels of economic ability to influence the public policy in the country. Instead, tax cuts of up to 50 percent were offered to the rich people thus leading to a situation where the economy started to grow, and the rate of unemployment was reduced to below 2 percent in the country (Huber \& Stephens, 2001).

\section{Analysis and Critique of the Public Policy Based on the Social Citizenship}

It has been noted above that the formulation and the implementation of the public policy were greatly dependent on the social citizenship whose hallmark was the social citizenship ideals that were substantially supported by T. H. Marshall. Thatcherism focused on a number of elements that informed the policy that was used. Thatcher, the Prime Minister of Britain during the majority of the 1980s, concentrated on a number of factors that were in stark contrast to the views that were held by Marshall and the other social democrats (Green, 2002). Thatcherism 
offered a formidable critique to the need to focus on the provision of the welfare benefits to the majority of the people. Marshall focused on a whole range of rights, for instance, a modicum of security and economic welfare to the right of the citizens to be able to share fully in the social heritage of the country. Thatcherism, on the other hand, focused on the different ways through which the financial discipline ,as well as free markets, would be encouraged, where tax cuts would be undertaken as well as a individual level of the privatization of the different operations of the government and the firm control over the expenditure of the state. Thatcherism is against the belief that was held by Marshall as regards to the need to provide the economic welfare and the security of the people (Murray, 2007). The different programs that were used in offering the reprieve to the poor in Britain were faced with significant cuts in the spending. It can thus be noted that the economic abilities of the people was not the primary driving force in the making of the policies but the policies were also affected by the need to be able to ensure that there was a great level of support due to the populism that was advocated for by Thatcher.

Secondly, the social welfare actually constrained the people who have the low economic ability from the involvement in the public policy implementation and formulation due to the fact that they would be subject to partial or passive entitlements that gave them no other obligation to be involved in the public life (Ben-Ishai, n.d.). The culture of the dependency that arose from the passivity of the citizens lead to a situation where the people who have low economic abilities cannot be involved in policy making as they will depend on the welfare benefits that are offered by the state.

Finally, there has been considerable criticism with regards to the ability of the welfare state to eliminate the constraints that prevented the different individuals of differing economic ability from behaving in an autonomous manner (Ben-Ishai, n.d.). It must be noted that the welfare systems that are used in the different states lead to a situation where after the provision of the resources has been done, there is an enormous amount of social control, especially, due to the fact that there will be a great level of disciplinary power (social control) over the recipients of the social welfare support thus their autonomy to participate fully in the formulation and the implementation of the public policy will be significantly reduced.

\section{CONCLUSION}

Citizenship can be defined as the judicial and political status given to individuals as equal members of a national community that both oblige them to undertake personal responsibilities and entitle them to individual rights. Public policy relates to nine main areas in the efficient running of society. T. H. Marshall's main 
argument was related to the fact that the ideal experience for the citizenship was where the citizens would have a wide access to the civil rights, political rights as well as the social rights in the given state where they lived or occupied. Marshall's views on social citizenship greatly bordered on the social democracy as it had been noted that he was a practicing egalitarian liberal who believed in the fact that the PWWS that was enacted by the United Kingdom's Labour government was an example of democratic socialism due to the fact that it entailed a significant amount of welfare state in it. However, the social citizenship conception by T. $\mathrm{H}$. Marshall has been criticized as being too ideal. There are a number of scholars who have considered the effects of the economic abilities of the citizens in influencing the development and the implementation of the public policy. Lipsmeyer noted that the economic climate that has an effect on the economic abilities of the citizens had a great influence on the formulation as well as the implementation of the public policy. The influence of the citizens' economic abilities in the formulation and implementation of public policy has been noted in a number of different countries in the world. The economic difficulties that were faced by the people in Denmark due to the rise in the rates of the unemployment led to formulation and implementation of public policy that were geared towards the reduction in the dependency on the welfare. The social welfare actually constrained the people who have the low economic ability from the involvement in the public policy implementation and formulation due to the fact that they would be subject to partial or passive entitlements that gave them no other obligation to be involved in the public life.

\section{References and notes:}

Ben-Ishai, E. (2006). Toward a Revised Conception of Social Citizenship: An AutonomyFocused Model. Paper presented at the Association for Political Theory Conference, Indiana University, Bloomington, IN. http://www.cpsa-acsp.ca/papers2007/Benishai.pdf

Dwyer, P. (2010). Understanding social citizenship: themes and perspectives for policy and practice (2nd ed.). Bristol: Policy Press.

Esping-Anderson, G. (1990). Three Worlds of Welfare capitalism. Cambridge: Polity Press.

Evers, A. (2013). Social policy and citizenship: the changing landscape. Oxford: Oxford University Press.

Green, E. H. H. (2002). Ideologies of Conservatism: Conservative Political Ideas in the Twentieth Century. Oxford: Oxford University Press.

Huber, E. \& Stephens, J. D. (2001). 'Development and Crisis of the Welfare State', in Politics of Welfare States after the Golden Age. Chicago: University of Chicago Press.

Kolberg, J. E. (1992). Between work and social citizenship. Armonk, N.Y.: M.E. Sharpe.

Lipsmeyer, C. S. (2011). Booms and Busts: How Parliamentary Governments and Economic Context Influence Welfare Policy. International Studies Quarterly, 55(4), pp. 959-980. 
Marshall, T. H. (2005). Citizenship and Social Class, in C. Pierson, F. G. Castles, The Welfare Reader, S. pp. 32-41.

Murray, G. (2007). Who is afraid of T. H. Marshall? Societies without Borders, 2, pp. 222242.

Schlesinger, M. (2011). Making the Best of Hard Times: How the Nation's Economic Circumstances Shaped the Public's Embrace of Health Care Reform. Journal of Health Politics, Policy \& Law, 36(6), pp. 989-1020.

Seeleib-Kaiser, M. (2001). Globalization and the German Social Transfer State. German Politics, 10(3), pp. 103-118.

Whitaker, E. A., Herian, M. N., Larimer, C. W., \& Lang, M. (2012). The Determinants of Policy Introduction and Bill Adoption: Examining Minimum Wage Increases in the American States, 1997-2006. Policy Studies Journal, 40(4), pp. 626-649.

\section{Summary}

\section{Impact of Citizens' Economic Status on Policy Formulation and Implementation}

\section{Joash Ntenga Moitui}

Thematic Centre for Governance and

Regional Integration, Cameroon

There are many factors that are considered in public policy implementation. This paper seeks to explore the economic abilities of citizens influence on the formulation and implementation of public policy. Behavioural economics has been used to explore individuals behavioural antecedents especially in decision making. The paper explores this concept coupled with how economic ability and behavior of citizens, particularly the middle class can play in enlightening policymakers. The general purpose of the paper will be to find out how these factors influence the making and execution of policy. It uses Thomas Humphrey Marshall social concept to argument, critique and analyze how policymakers react to the nature of the society.

Keywords: Public Policy, Social Citizenship, Behavioural Economics, Thomas Humphrey Marshall Concept 